\title{
Revealing the past: how science is unlocking cartographic secrets
}

\author{
Nick Millea \\ Bodleian Libraries, University of Oxford, nick.millea@bodleian.ox.ac.uk \\ David Howell \\ Bodleian Libraries, University of Oxford, david.howell@bodleian.ox.ac.uk
}

\begin{abstract}
Although advanced imaging and analytical techniques have long been available, it is only over the last three to five years that they have been more generally applied to serious study of library materials. This has been driven by incredible advances in technology which allow for non-invasive, non-sampling, non-contact methods to be designed specifically with the curators' concerns for the safety of the material in mind. At the same time the curators' increasing awareness of what is possible has increased the demand for such services.

For maps, one of the outstanding developments has been hyperspectral imaging. This is a technique where an item is scanned and each 'pixel' represents a full colour spectrum, commonly 400-1000 nm. The large files produced in this way can be interrogated by sophisticated software to reveal erasures and obscured areas of detail invisible to the naked eye. Hyperspectral imaging can also be used for identifying pigments, especially organic materials. This technique is completely safe if applied correctly and with continuous dialogue between curators, conservators and the people carrying out the analysis/imaging.
\end{abstract}

It is now possible to employ science to date cartographic material, and to infer where maps might have been made. We can also use hyperspectral imagery to reveal underlying cartographic content previously obscured from view.

This paper will examine how these techniques have been employed with varying degrees of success on the late medieval Gough Map of Great Britain, and two manuscript English estate maps, all items held within the Bodleian Library's collections.

\section{HYPERSPECRTAL IMAGING AT THE BODLEIAN: AN INTRODUCTION}

The way we experience the world is not unique. Other living creatures have different sensory receptors to humans; different abilities to hear high pitched sounds and the ability to smell very low concentrations of odour for example. The same is true for vision. We have just three colour receptors: red, green and blue, whilst other species have different numbers. An extreme example is the mantis shrimp. Being able to see four or five wavelengths in the ultra-violet region and also into the infra-red region of the electromagnetic spectrum as well as seven different sensors across the visible wavelengths will give the shrimp a very different version of the world to us (plus a very different appreciation of art!).

Most imaging, or digitisation, has as the main aim of creating as accurate a reconstruction or representation as possible for the viewer and is focussed on visual aesthetic. This means concentrating on the way the human eye responds to colour. Other imaging can show things invisible to the human eye, the most commonly known being in medical imaging such as X-radiography and Magnetic Resonance Imaging (MRI).

At Easter 2014 the Humanities Division within the University of Oxford was lucky enough to receive a grant from the internal University Fell Fund to purchase imaging equipment more akin to the shrimp's 'eye' than the human eye. Hyperspectral imaging is the process in which image data is captured at many frequencies across the electromagnetic spectrum to produce a complete reflectance spectrum for each pixel. The Headwall imaging system captures all the spatial (1600 pixels) and spectral data (972 bands 
from 400-1000 nm) that can be seen within the field of view of the imaging device. This new set of virtual eyes gives users a more complete view of any type of reflecting material than the human eye alone. It can be used to reveal information about both the materiality of objects (e.g. pigments, lichen, and binder) and hidden text or pictorial information in built heritage as well as objects in a museum, a library, or a university.

The equipment produces a great deal of data, effectively a stack of 972 high resolution images, each at a specific wavelength. While scanning through each of the images can sometimes reveal hidden information it is often necessary to use computational analysis to tease out detail. The Library is lucky to have access to ENVI software, and extremely powerful computer program designed specifically for analysing hyperspectral data. The software carries out a number of processes on the data to try to group similar spectra together. One of the most powerful techniques is called Principal Component Analysis (PCA) but ENVI has many algorithms which can be applied to tease out understandable information from the vast amount of data.

The equipment has been used most generally on codices; bound books. Sometimes the data can be analysed very quickly and a result delivered to the researcher within hours. In most cases people are looking for hidden texts or under-drawings and if these become visible one has an immediate and positive result. But the first object ever scanned in the Bodleian, even before the equipment was purchased, was the Gough Map. This object was chosen as a challenge for the technology as the map is very large and it is not entirely clear whether there is information to be uncovered. The data collection was extremely successful but even after two years we are still exploring the data to reveal more information.

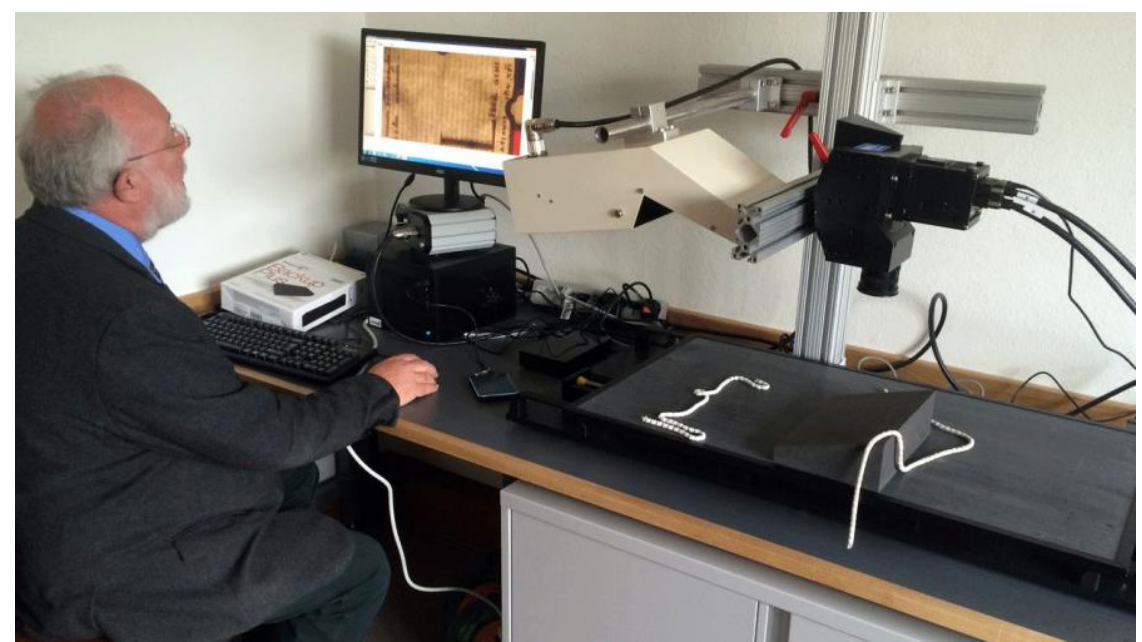

Fig. 1 Here is the equipment. In essence the sensor looks at a very narrow band 1600 pixels long and one pixel in width. The sensor measures colour from $400 \mathrm{~nm}$ (near the UV end of the spectrum) up to

$1000 \mathrm{~nm}$ (in the IR region) at something around $1 \mathrm{~nm}$ intervals. This means that each pixel is

represented by 972 'measurements' and gives a huge amount of calibrated colour information.

To place the research in its institutional context, the Bodleian Library, the library of the University of Oxford, was founded by Sir Thomas Bodley in 1602. It has become Europe's largest university library, holding twelve million books, and well in excess of 1.25 million maps. The Library's maps fall within the Department of Special Collections, administered from the recently-refurbished Weston Library, located in Oxford city centre. Both authors are based in this building.

\section{THE MAPS}


To prepare for the ICA History of Cartography gathering in Dubrovnik, the authors decided to select three manuscript maps from the Library's collections for hyperspectral treatment. The basic premise being to reveal detail unseen to the naked eye. As alluded to above, some preliminary work had already been undertaken on the Gough Map, but in order to broaden the research pool, two unheralded and virtually unknown manuscript maps were set aside for data capture.

\section{The Ascott Park map}

Firstly, the Ascott Park map, featuring a long-disappeared estate in South Oxfordshire (about $15 \mathrm{~km}$ south-east of Oxford). This map dates from the early eighteenth century, and was made by the prolific local land surveyor William Burgess. All that remains from the estate is an ornamental gateway bearing the inscription si bonus es intres: si nequam nequaquam, or if good come in: if wicked, by no means, and this gateway has been reconstructed within the Weston Library, opened to the public in March 2015. The gateway and its message are particularly apposite, representing the point at which only individuals bearing a Bodleian Library reader's ticket can move from the public area of the building to those areas set aside for Library readers. The map itself was also purchased by the Bodleian from a private individual in 2015, thus reuniting both manuscript and masonry. The map measures $133 \times 84$ $\mathrm{cm}$.

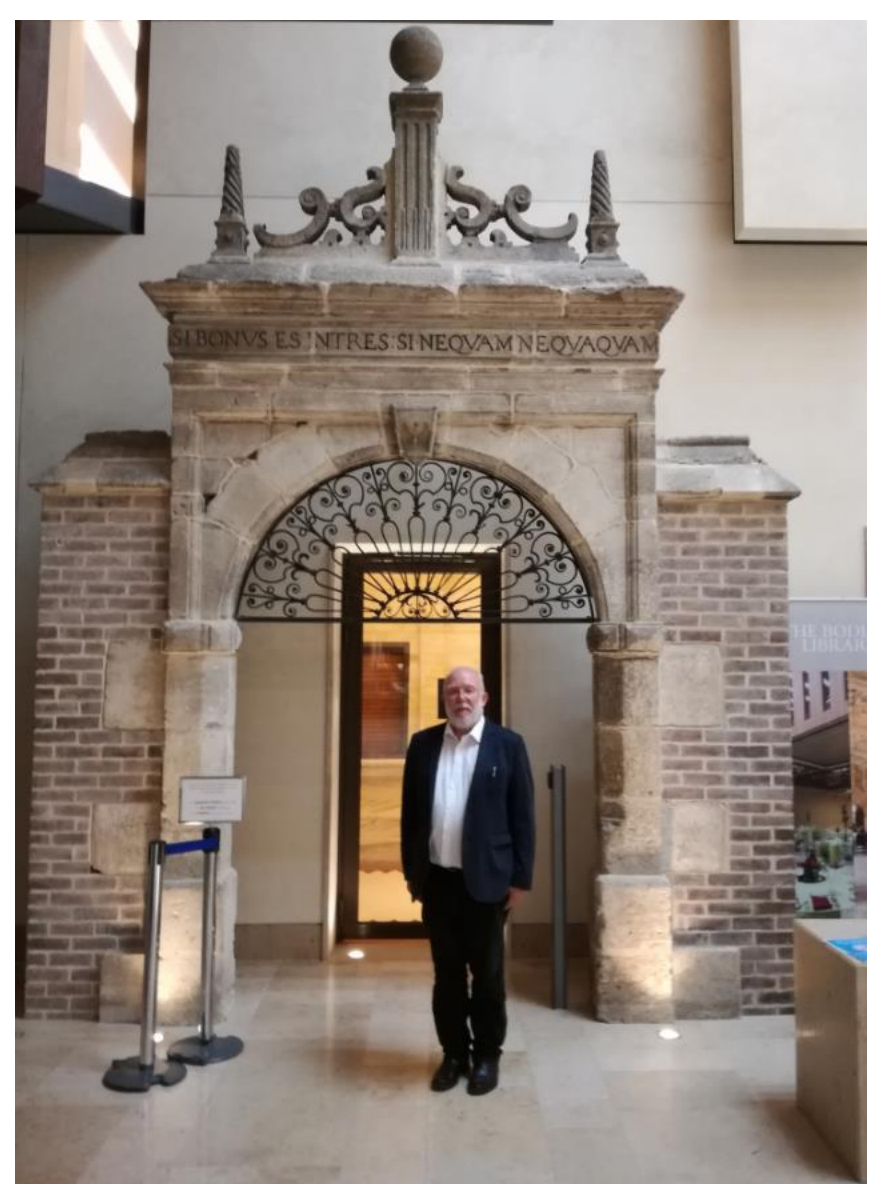

Fig. 2 David Howell standing beneath the Ascott Park gateway 


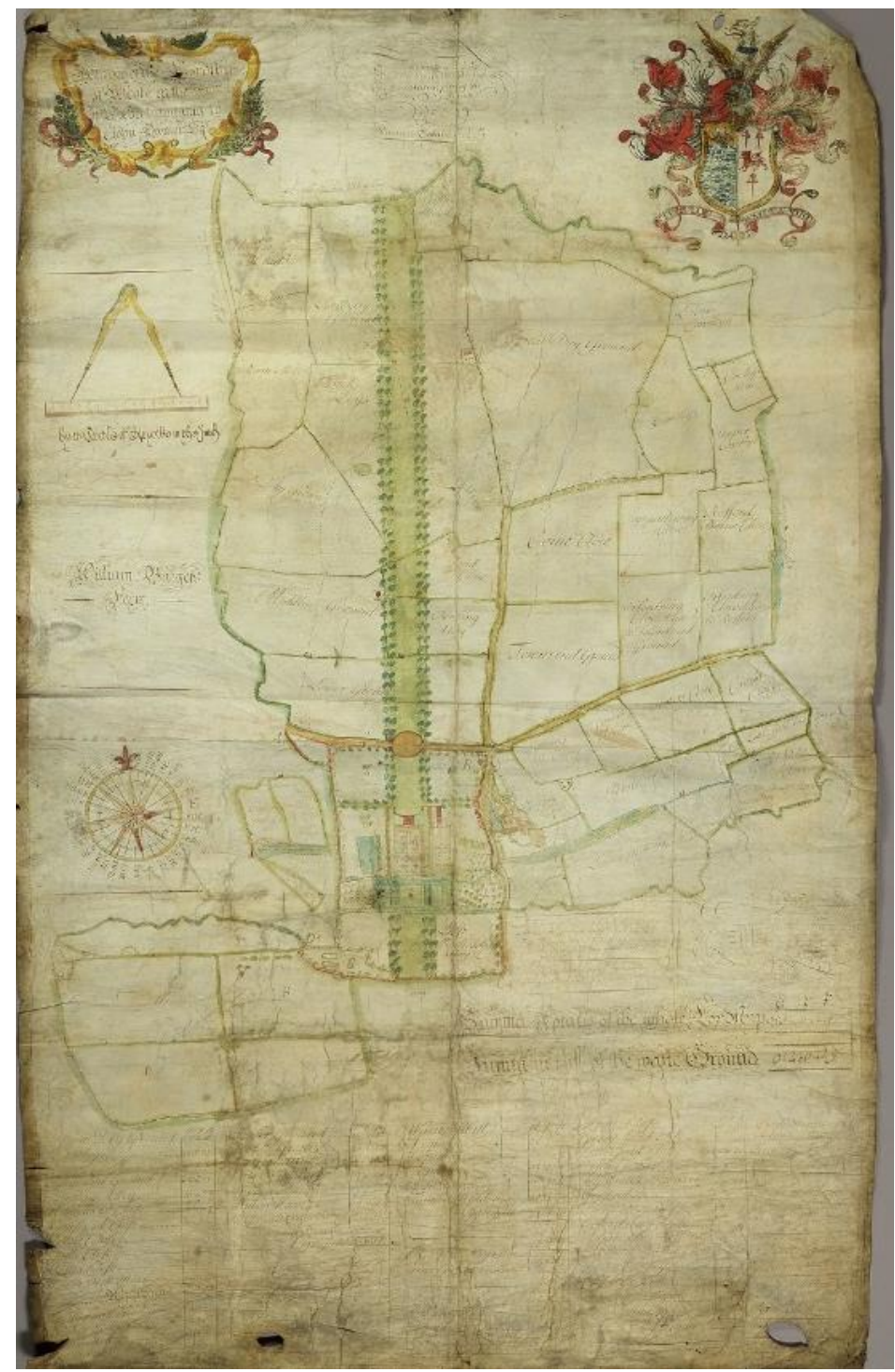

Fig. 3 Ascott Park estate map by William Burgess 


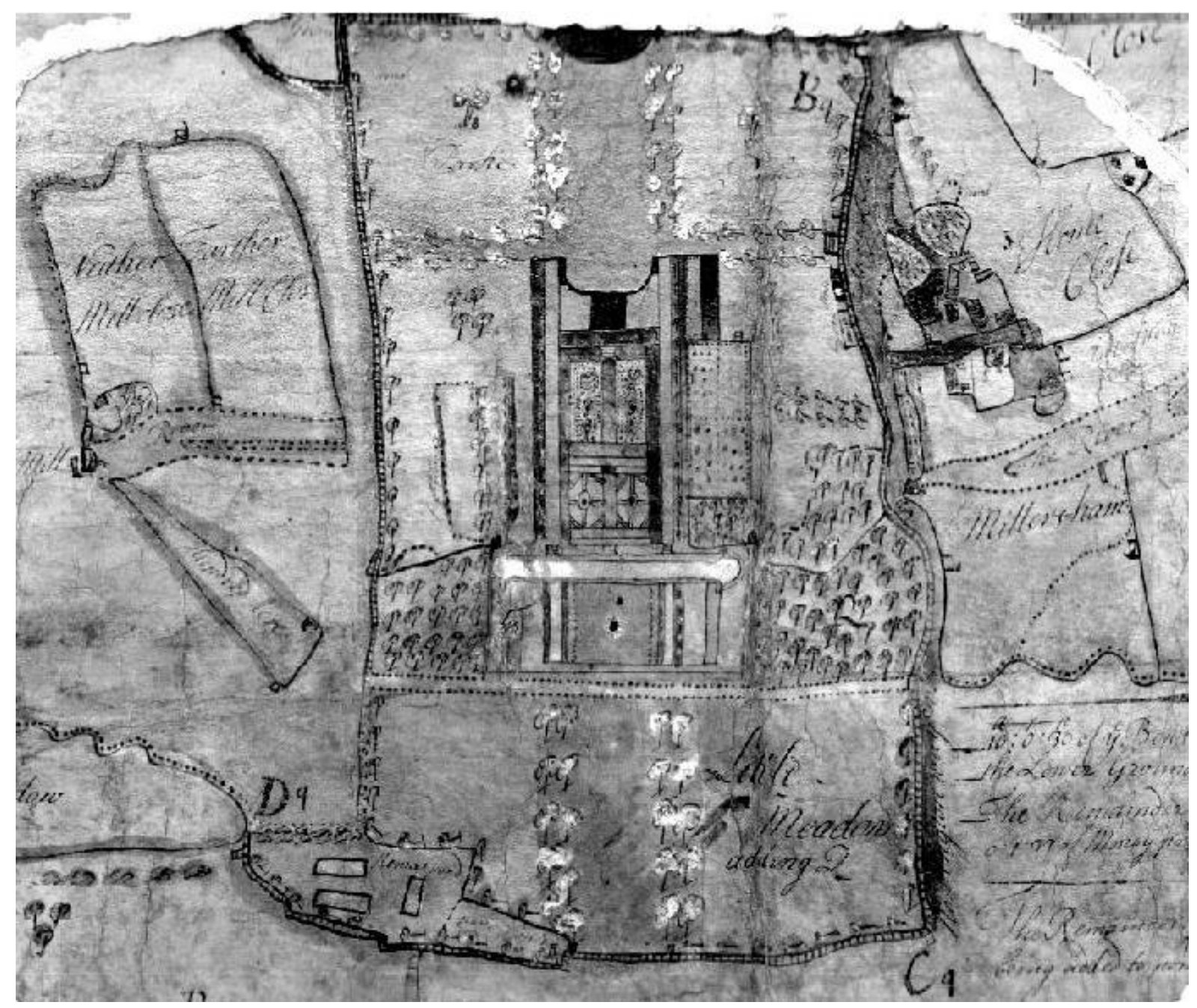

Fig. 4 Hyperspectral image of the area around Ascott Park's main house

The intention of the hyperspectral work was to help identify the location of the gateway on the map. This objective has yet to be met, however, although the map's text is now clearly legible, and as can be demonstrated by Fig. 4 above, the map's detail has become considerably clearer. The 'go to' series of algorithms, essentially ways that the computer searches for information in all this data, within the ENVI software are grouped together in one semi-automated procedure called the Spectral Hourglass Wizard. The hourglass processing flow uses the highly detailed nature of hyperspectral data to find the most spectrally pure, or spectrally unique, pixels (called endmembers) within the dataset and to map them. This processing flow begins with reflectance input data. Then the 'wizard' looks for 'endmembers' that are similar across the whole spectrum (including areas not visible to the human eye) and maps these, often giving several different outputs. It is then up to a human to look at these outputs to decide which ones give the most useful information.

\section{The "Cheshire Acres" map}

The second manuscript selected was an altogether different challenge. This map has yet to be identified geographically. The text is in English, and it is believed to represent an English estate. But where? Numerous attempts have been made to associate the cartography with a precise geographical location, but without success. All that is known is that the map includes measurements in "Cheshire acres", there is a North arrow to give a sense of direction, and the text that is legible with the naked eye suggests the manuscript is a copy of a 1641 original. The map measures 68 x $84 \mathrm{~cm}$. 


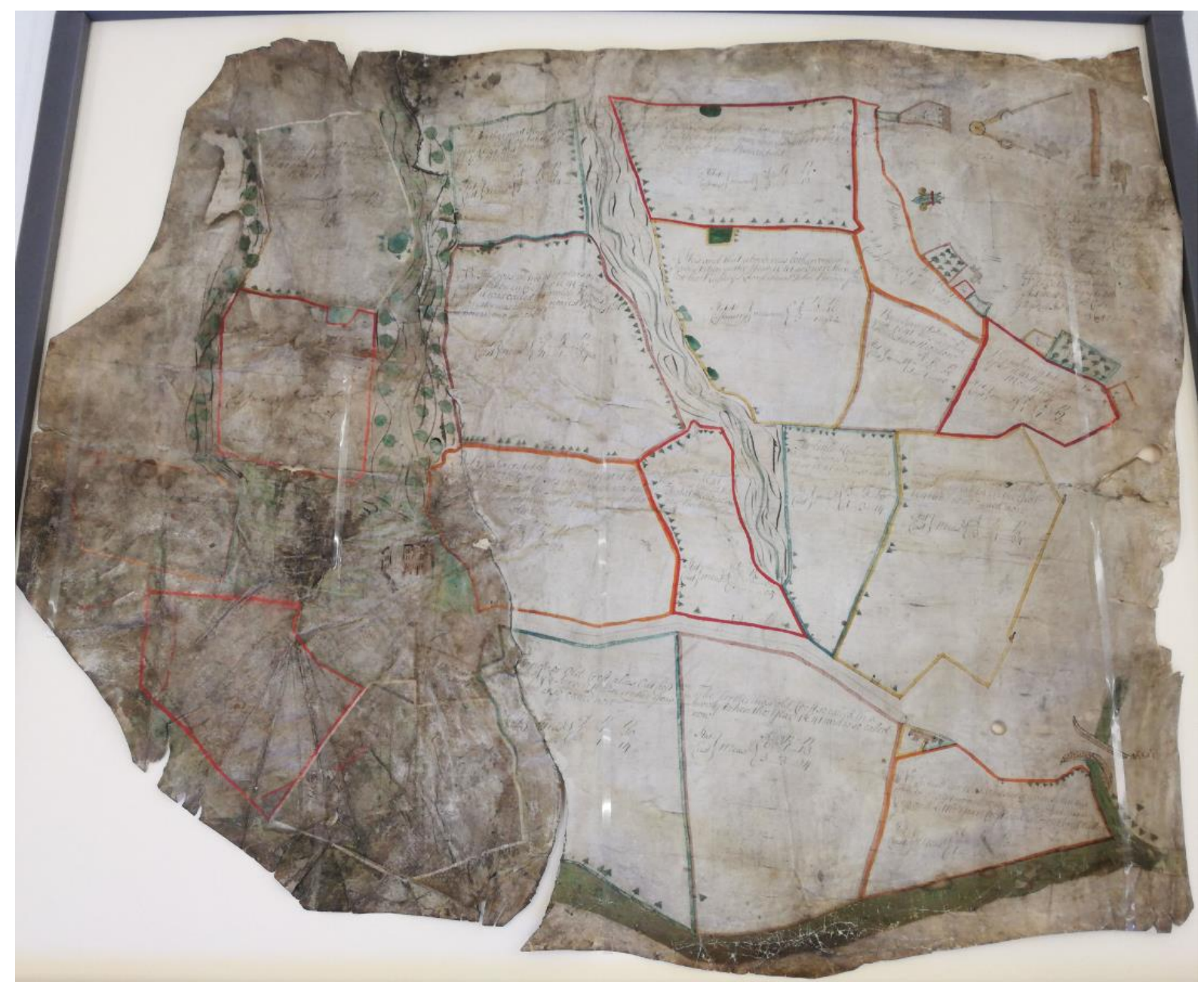

Fig. 5 The "Cheshire Acres" map, copied from a 1641 original

The hyperspectral imagery has made clearer some of the map's detail, but the exact location of this estate remains unknown. The darker, much-damaged left-hand side of the map features a large house or hall, but as yet, the accompanying text cannot be read, and so the hall continues to be nameless. The clearer, right-hand section does however give up some clues. Numerous field names are revealed, always presented with the rider equating to "formerly known as ... in 1641 but now called ..." whereupon the text ends and a frustrating blank space can be seen. There is also a house clearly named "Scotland", but alas such a house no longer appears to exist. One clue, however, is the appearance of a "Mr Harrop", and Harrop is a surname which can be confidently be pinpointed to a small geographical area, principally to the south of Manchester, in other words north-east Cheshire, a convenient coincidence given the presence of Cheshire acres on the map (see Fig. 5). 


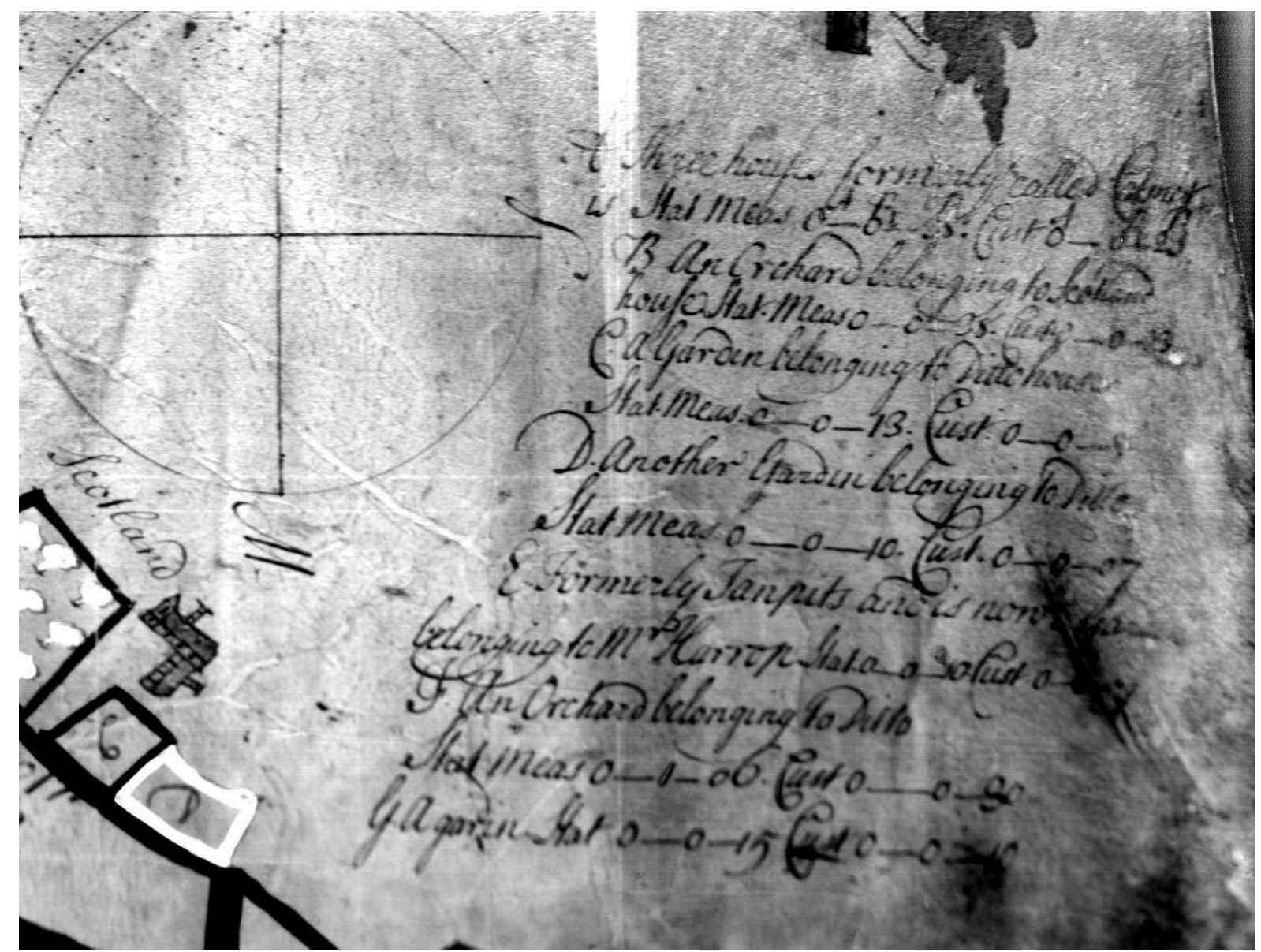

Fig. 6 Extract from the "Cheshire Acres" map, showing the house known as Scotland and naming Mr Harrop

Fig. 6 above has been derived from the ENVI Spectral Hourglass Wizard, and the descriptive text identifies a number of the small parcels of land depicted on the map. 


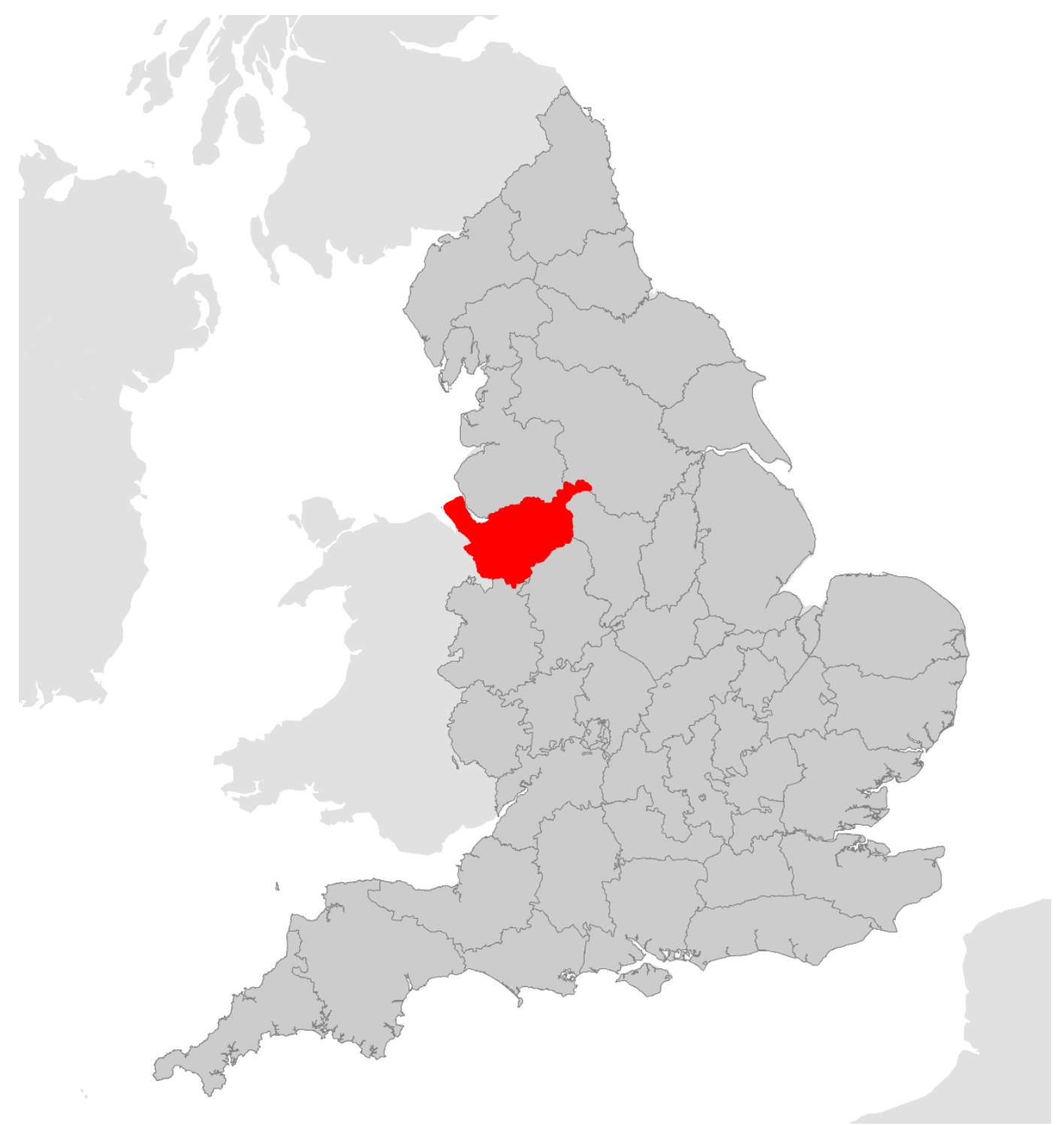

Fig. 7 Location of Cheshire 


\section{Ppublicprofiler}

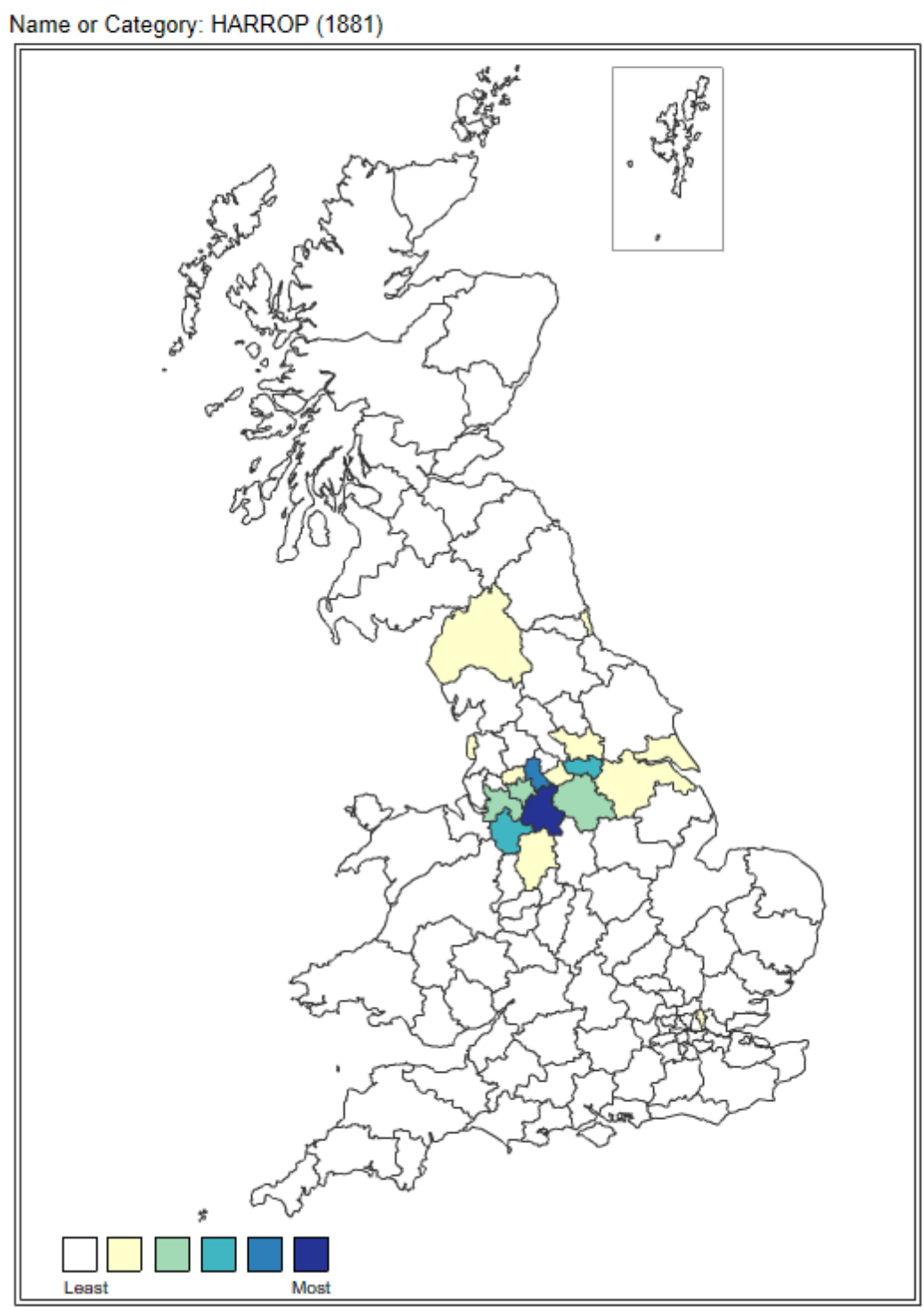

Fig. 8 Surname locations from the 1881 census of Great Britain: distribution of the surname 'Harrop'. Source: University College London

Figs. 7 and 8 place the successful research to date into geographical context. Cheshire is located in the north-west of England, and University College London's investigation into surname distribution focuses on the 1881 census and the whereabouts of those named Harrop entered onto that census. Clearly there is a degree of correlation which gives grounds for optimism for future exploration.

The principal house on the map, however, remains unidentified, despite experimenting with a variety of spectral combinations (see Fig. 9). This image was derived from the ENVI Spectral Hourglass Wizard and using 'false colour' to highlight differences. 


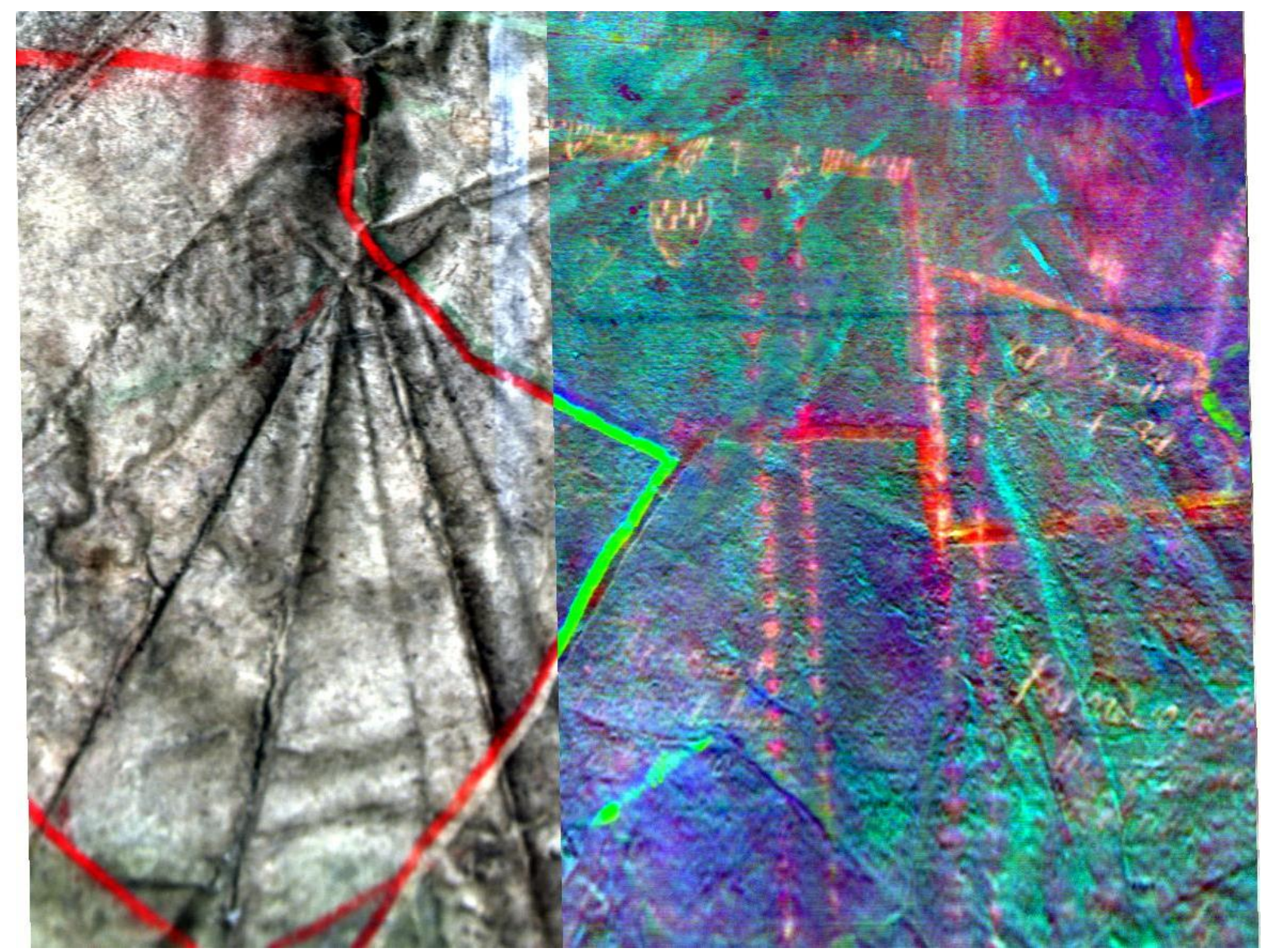

Fig. 1 Combining spectra around the unidentified main house on the "Cheshire Acres" map

\section{The Gough Map}

Much has been written about the late medieval Gough Map of Great Britain, described by Helen Wallis as "The most remarkable cartographic monument of medieval England" (Wallis 1994: 13-14). The map has its own website (Linguistic geographies 2011), which offers the opportunity to explore the manuscript in much greater detail.

The map measures $56 \times 117 \mathrm{~cm}$ and has been held in the Bodleian since 1809 when it was bequeathed to the Library by Richard Gough, hence its name. The map is widely considered to be the earliest surviving map to show the island of Great Britain in a geographically recognisable form. It consists of around 600 place names and over 200 rivers, and clearly depicts late medieval England and Wales with a certain degree of familiarity. Scotland is somewhat less convincing. This iconic cartographic design was very much the template for maps of Britain until the latter part of the sixteenth century.

Since high resolution imagery became available in the first decade of the twenty-first century, research interested has abounded, hence the reason for the map to be subjected to hyperspectral treatment.

In 2012, a "Gough Map panel" was set up by Catherine Delano-Smith (Delano-Smith et al 2017: 1) with a view to developing research into one of the history of cartography's more enigmatic maps. Delano-Smith's team included Peter Barber, Damien Bove, Matthew Champion, Christopher Clarkson, Paul Harvey, Nick Millea, Nigel Saul, William (Bill) Shannon, Christopher Whittick and James Willoughby. This initial group has subsequently reached out to the scientific community, and in particular David Howell; the University of Durham's Raman spectroscopy team of Andrew Beeby, Kate Nicholson and Tony Parker; the 3-D scanning outfit from Madrid's Factum Arte - Adam Lowe, Carlos Bayod and Arthur Prior; and more recently the hyperspectral research undertaken by David Messinger and his colleagues at the Rochester Institute of Technology (RIT), New York. The first manifestation 
of this group's work can be found in an article published in 'Imago mundi' (Delano-Smith et al 2017: $1-36)$.

Hyperspectral imagery of the map was initially captured in January 2015, but early results proved inconclusive. However, once the striking discoveries made by the Lazarus Project on the Beinecke's 1491 Martellus map of the World were reported (Van Duzer 2015, 2016), the Bodleian was able to open communications with hyperspectral colleagues in the United States, and a partnership with RIT was born.

On 30 June 2016, Oxford's Wolfson College hosted the Science and Engineering in Arts Heritage and Archaeology (SEAHA) special seminar in Multispectral and Hyperspectral Imaging, an event attended by members of the Rochester team, which included a paper by David Messinger, Director, Chester F. Carlson Center for Imaging Science, RIT. This presentation was partly illustrated with slides featuring the Gough Map.

Demonstrating how flexible hyperspectral imaging can be, Messinger presented an image showing the centre of the Gough Map with north at the top. Using Principal Component Analysis (PCA) he was able to demonstrate very clearly how two different reds have been used on the map, seen below. One red shows up as Hadrian's Wall and as the urban vignettes dotted across the map (red in the image); whilst the purple writing running from north to south on the image below, also shows up as red to the naked eye.

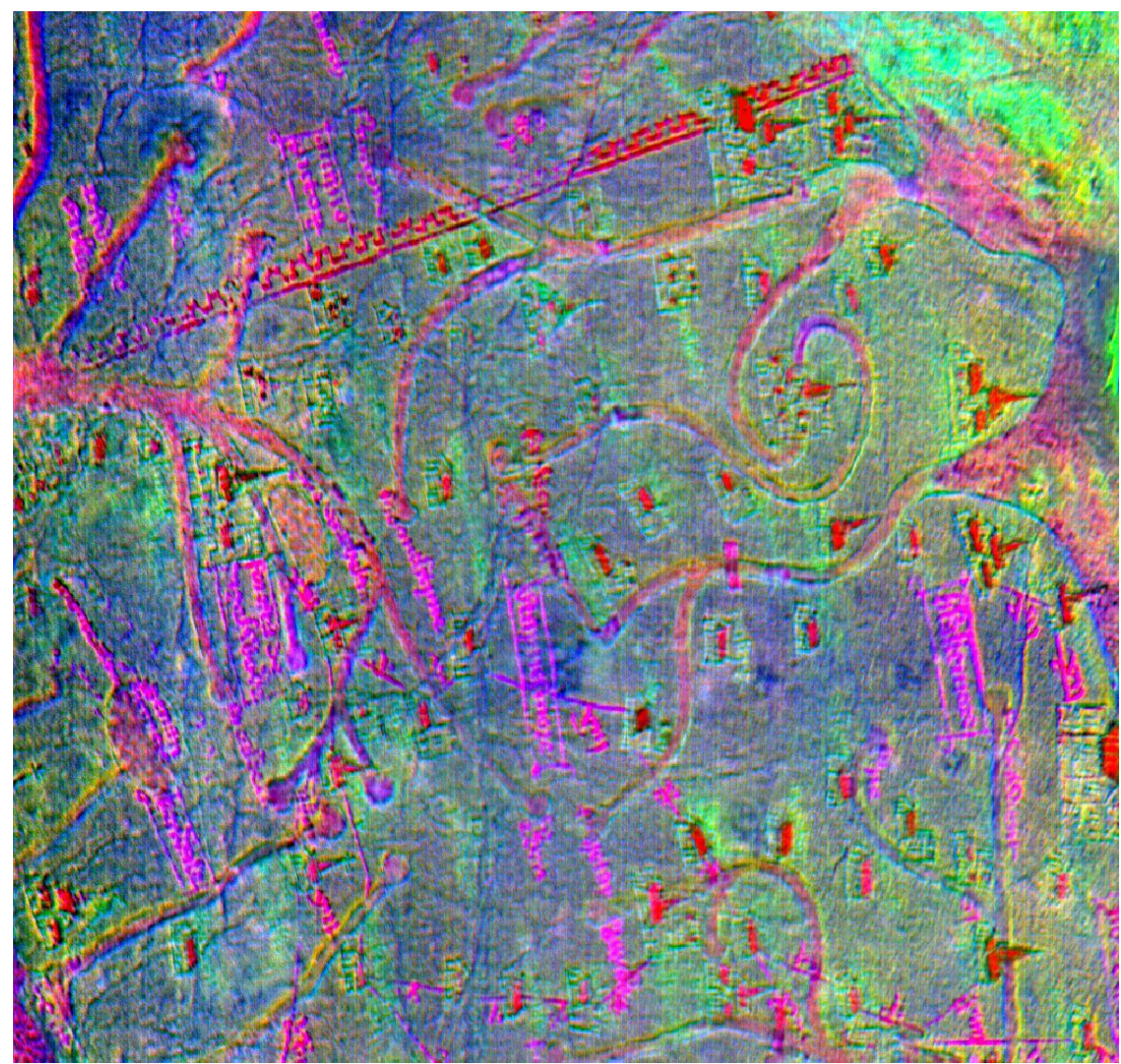

Fig. 10 The Gough Map after PCA - note the two different rendering of reds

The suggestion is that different pigments were used in the red inks.

A further manifestation of the value of PCA can be seen when comparing a conventional Red/Green/Blue image of the Humber estuary with a PCA image. Where the naked eye cannot 
differentiate between different pigments, hyperspectral techniques clearly demonstrate that different inks must have been used for the greens employed to colour the map's watercourses.
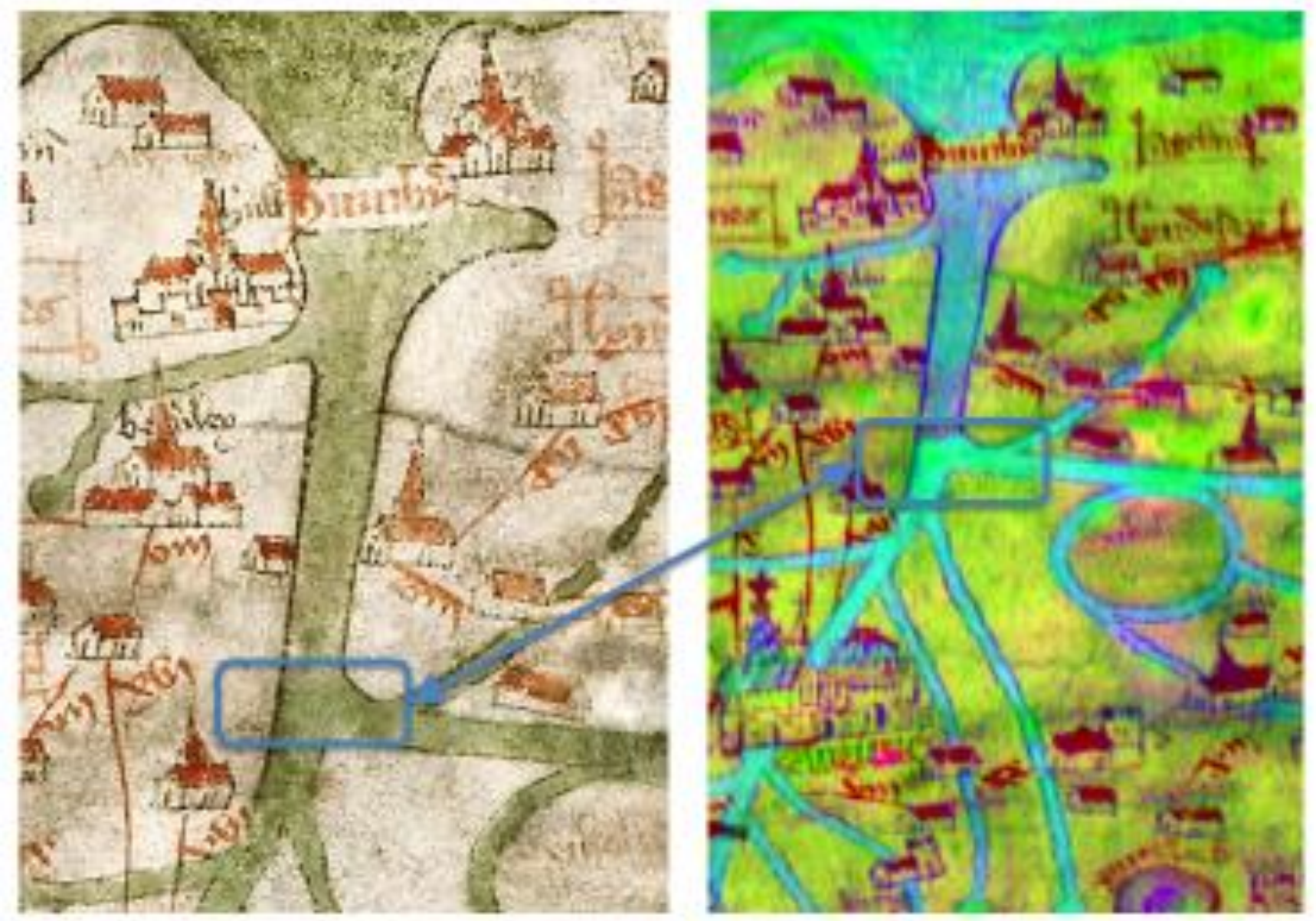

Fig. 11 Note the different greens in the River Humber - the PCA image is on the right

What may be at play here is that the mapmaker(s) are differentiating between tidal and non-tidal waters, although the Humber's tidal range does extend much further inland. Might it refer to river depth? Or a crossing point? All of these options may be worth further research.

Another hyperspectral technique is Spectral Angle Signature matching (SAM), and the illustration below shows how this can work, examining an area of north Wiltshire, just below the "albus equus" label, or (Vale of) White Horse. 

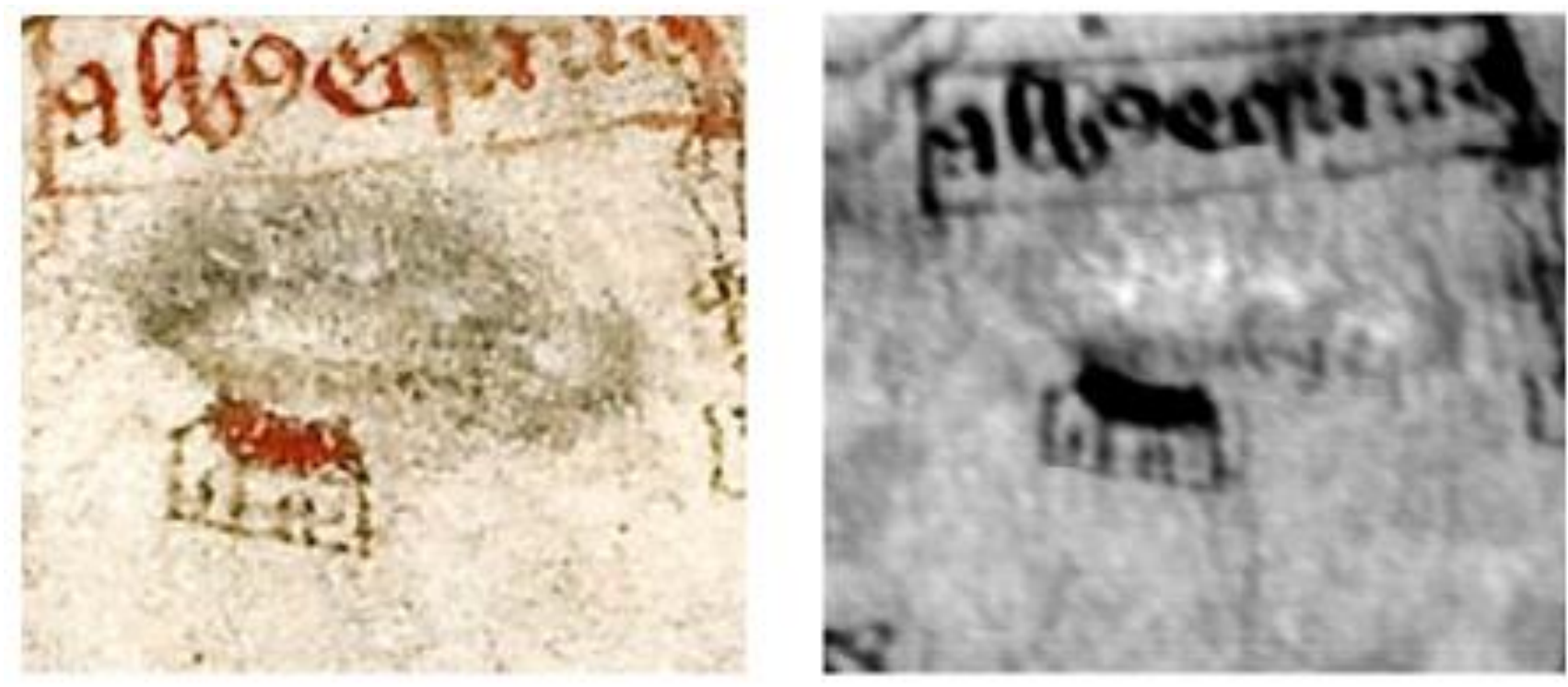

Fig. 2 Note the emerging text using the SAM image is on the right

Because the text is more similar to the reference spectrum than the "blotch", it stands out more on the right-hand image, so some writing can be seen to the top right of the rooftop.

Much of what Messinger presented had been previously unseen by the authors of this paper, and with Messinger's permission, his slides were shared with the Gough Map panel, Delano-Smith and Bove enthusiastically engaging with the challenges and opportunities revealed. In the intervening six months, progress has been made with the Rochester team responding to queries from the UK-based panellists.

Since the Bove/Messinger communication channel has opened, the RIT team has been looking towards the application of novel image processing algorithms to the map image, with the intention of identifying both clustering of materials such as substrate, inks and pigments. There is also the option to "sharpen" features on the map.

Latest developments have seen a labelling exercise initiated, whereby all features on the map are colourcoded, and different colours have been allocated to: buildings or rooftops; rivers; Hadrian's Wall; red text; and "older" ink. To date, about one third of the map has been completed, as exemplified below in Fig. 13.

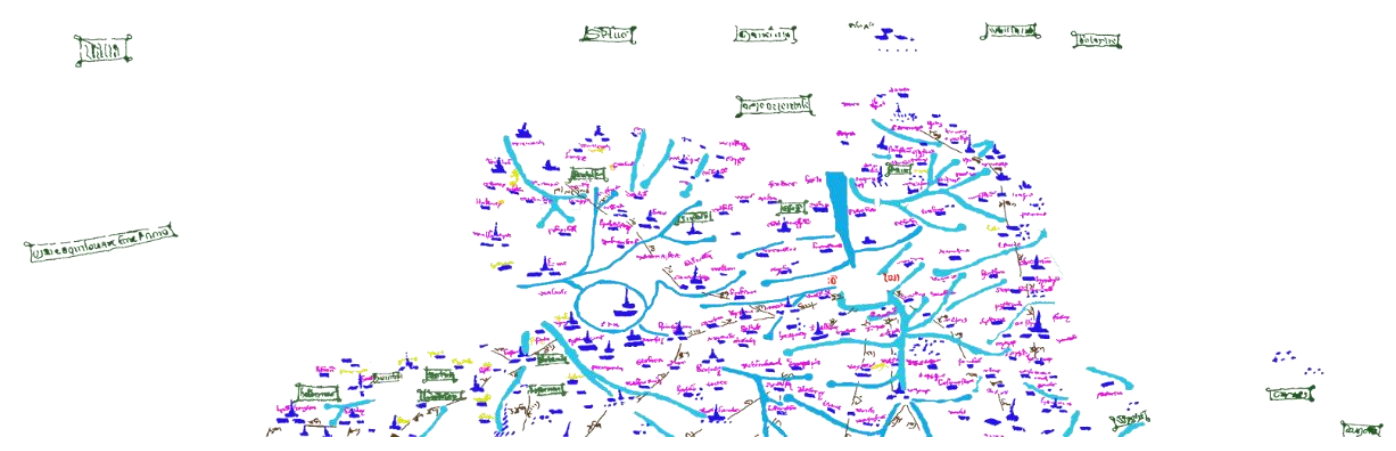

Fig. 13 Labelling the south-east corner of the Gough Map

These labels establish what are referred to as "ground truths" by the RIT team, which can be employed to assess the performance of what are referred to as "pattern recognition algorithms". In turn, this permits RIT specialists to interrogate inks and their pigments, as well as the material on which the map 
is made. The intention is to make all this data publicly available for further testing, safely secured by those ground truths which give the data a set of solid starting reference points.

\section{CONCLUSION}

The hyperspectral imaging of these maps has been successful in showing that additional 'knowledge' can be gained by looking at the images created in ways which are simply not possible to see with the naked eye. This is a fairly alien concept to those who have historically wanted to produce images that are as close to the original as possible. As such it will take time and experience to fully appreciate the value of these techniques.

The aspiration that hyperspectral would answer all our queries has not materialised. But it may do in the fullness of time. We have not spotted the gateway on the Ascott Park map; and we have not definitively identified the location of the "Cheshire Acres" map. The Gough Map, however, has started to give up some of its secrets, and the more the RIT consider the imagery they have, the more will be revealed. Those nuggets of information coming back across the Atlantic are starting to excite the Gough Map panel. Those at RIT are beginning to benefit from input and questions delivered by the Gough Map specialists, and gradually more data informs us of the map's compilation and content. Neither team can work in isolation - RIT need input from the panellists, the panellists need to know what the hyperspectral technology is capable of delivering. This is all part of the cross-fertilisation of ideas between the scientists and the curators and historians. We have seen that the Martellus map has produced some stunning results. Perhaps we can hope for something similar with the Gough Map?

We know it is now possible to employ science to date cartographic material, and to infer where maps might have been made. We know we can also use hyperspectral imagery to reveal underlying cartographic content previously obscured from view. We need to press on with the research to extract as much new information as possible from these manuscripts, and embrace the science that is now available. A decade ago, a partnership such as this would have been beyond the academic community's research aspirations.

\section{REFERENCES}

Cheshire Archives \& Local Studies. e-Mapping Victorian Cheshire

http://maps.cheshire.gov.uk/tithemaps/Default.aspx . Last accessed 9 Dec 2016

Delano-Smith C (2017) New light on the medieval Gough Map of Britain. Imago mundi 69(1): 1-36

Linguistic geographies: the Gough Map of Great Britain (2011)

http://www.goughmap.org/ . Last accessed 9 Dec 2016

University College London ([2008]) Great Britain Family Names Profiling.

http://gbnames.publicprofiler.org/ . Last accessed 9 Dec 2016

Van Duzer C (2015) Graphic record of a lost wall map of the World (c. 1490) by Henricus Martellus. Peregrinations : journal of medieval art \& architecture 5(2): 23-47

Van Duzer C (2016) Multispectral imaging for the study of historic maps : the example of Henricus Martellus's World map at Yale. Imago mundi 68(1): 62-66

Wallis H 1994 Historians' guide to early British maps. Royal Historical Society, London 


\section{BIOGRAPHICAL NOTES}

Nick Millea has been Map Librarian at the Bodleian Library, University of Oxford, since 1992; he was previously Map Curator at the University of Sussex.

Nick is the Bibliographer for 'Imago Mundi', and a director of Imago Mundi Limited. He is also Chair of the British and Irish Committee for Map Information and Catalogue Systems (BRICMICS), and convenor of The Oxford Seminars in Cartography (or TOSCA). Nick's previous publications include numerous articles on both map librarianship and the history of cartography, as well as:

- The Gough Map : the earliest road map of Great Britain? Oxford : Bodleian Library, 2007.

- Street mapping : an A to Z of urban cartography : an exhibition in the Bodleian Library, February-April 2003. Oxford : Bodleian Library, University of Oxford, 2003.

- A celebration of 50 years of the British Cartographic Society / co-edited with Seppe Cassettari ... [et al.]. Ilkeston : British Cartographic Society, 2013.

David Howell has been at the Bodleian Library, University of Oxford since 2005 as Head of Conservation and Collection Care, and since 2012 Head of Heritage Science; he was previously Head of Conservation Research for Historic Royal Palaces.

David is a Trustee of Icon and The National Heritage Science Forum and is an accredited conservator. As Head of Conservation he oversaw the financing and conservation of the Gough Map of Great Britain and the Selden Map of China.

His current research is applying imaging and analytical techniques to heritage objects. 